\title{
Morphometric and Vascular Analyses and MMP-2 Expression in Bladders of Animals with Bovine Enzootic Haematuria
}

\author{
Anderson Barros Archanjo', Natalia Viana Tamiasso', Juliana de Castro Cosme', Maria Aparecida da Silva', \\ Leonardo Oliveira Trivilin', Julio Lopes Sequeira² \& Louisiane de Carvalho Nunes'
}

\begin{abstract}
Background: Bovine enzootic haematuria is a chronic, non-infectious disease caused by the ingestion of bracken Pteridium aquilinum that contain ptaquiloside, substance responsible for the development of neoplasms in combination with bovine papillomavirus infection. Studies examining metalloproteinases have shown that these enzymes may be useful as prognostic markers and many studies have correlated the intratumoural microvessel density and incidence of metastasis in a variety of cancers, including bladder cancer. This study aimed to evaluate the urothelial morphology and vasculature and quantify the expression of the enzyme metalloproteinase- 2 in the bladder lesions of bovine with enzootic haematuria.

Materials, Methods \& Results: Forty bladders with macroscopic lesions were subjected to routine histological processing. The material was stained using the Hematoxylin-Eosin (HE) and Weigert's resorcin-fuchsin staining methods. The morphometric analysis included the measurement of the total thickness of the urothelium. Microscopically, the lesions were differentiated as neoplastic or non-neoplastic, and the vascular changes were characterised as vascular proliferation, ectasia, dilation and thickening and the material stained using the Weigert's resorcin-fuchsin method was used to evaluate sclerosis and the vascular fibroelastosis. The metalloproteinase expression was evaluated using an anti-metalloproteinase-2 antibody. The main non-neoplastic lesions found in the urothelium included clear cell metaplasia, dysplasia, hyperplasia, haemorrhage, cystitis cystica and Brunn's nests and the neoplastic lesions were haemangioma, myxoma, transitional cell carcinoma, adenocarcinoma, in situ carcinoma and haemangiosarcoma. The urothelium measurements revealed differences between the epithelial thicknesses of bladders with and without neoplasms. The bladder vasculature evaluation revealed the frequent occurrence of different pathological aspects, such as vascular proliferation, dilation, expansion, ectasia and thickening; more severe vascular proliferation, thickening and fibroelastosis were observed in bladders with neoplasms. Metalloproteinase-2 expression was observed in the epithelial cells, fibroblasts, endothelial cells and smooth muscle cells present in the tumour tissue and was a significant increase in the expression of MMP-2 in the neoplasms of mesenchymal origin compared to the neoplasms of epithelial origin.

Discussion: The presence of a large variety of non-neoplastic lesions indicates the possibility that there are other factors concomitant to BEH involved. Epithelial hyperplasia and metaplasia, for example, could be the result of damage caused by bovine papillomavirus type 2 or even an altered urine $\mathrm{pH}$. Furthermore, it is believed that the bladder has the capacity to generate various types of neoplasms due to the different histological components of the bladder, thus enabling it to generate both mesenchymal and epithelial lesions. The thickness of the urothelium was greater in all the quadrants with neoplasms compared to the quadrants without neoplasms. These data revealed that it is possible to use less invasive diagnostic imaging methods to characterise bovine enzootic haematuria and to measure tumour progression based on the severity of vascular changes. The vascular proliferation and thickening were significant in bladders with neoplasms, which may be explained by the fact that tumours require an extensive vascular supply. In addition, many tumours release vascular growth factors and promote neovascularisation. The intensity of the immunostaining of metalloproteinase- 2 differed among the different types of neoplasms. However, due to the diversity of the tumours, it was not possible to establish a relationship between metalloproteinase-2 expression and tumour progression.
\end{abstract}

Keywords: bladder, cattle, immunohistochemistry, morphometry, neoplasm, vasculature.

DOI: $10.22456 / 1679-9216.100451$

Received: 20 February 2020

Accepted: 19 May 2020

Published: 13 June 2020

${ }^{1}$ Universidade Federal do Espírito Santo (UFES), Alegre, ES, Brazil. ²Universidade Estadual Paulista “Júlio de Mesquita Filho” (UNESP), Botucatu, SP, Brazil. CORRESPONDENCE: L.C. Nunes [louisianecn@gmail.com]. Departamento de Medicina Veterinária, Centro de Ciências Agrárias e Engenharias - UFES. Alto Universitário s/n. CEP 29500-000 Alegre, ES, Brazil. 


\section{INTRODUCTION}

Bovine enzootic haematuria $(\mathrm{BEH})$ is a chronic, non-infectious disease, characterised by the development of neoplasms in the bladder mucosa, caused by the spontaneous ingestion of Pteridium aquilinum. Affected animals present with intermittent haematuria, followed by death caused by anaemia $[17,31,37]$.

The ptaquiloside that is present in the plant is the main agent responsible for the development of neoplasms [1,11]. However, bovine papillomavirus type 2 (BPV-2) infection is commonly observed in animals with $\mathrm{BEH}$, and its action has been linked to the carcinogenic compounds found in plant $[34,46]$.

Interactions between the tumour and its microenvironment result in the production of proteolytic enzymes that are essential for tumour development [14,23], between them, metalloproteinase 2 (MMP-2) is capable of degrading collagen and plays an important role in tumour progression [5]. Studies examining MMP in various types of neoplasms have shown that these enzymes may be useful as prognostic markers [2].

Another important aspect of BEH includes the changes to the bladder vasculature. Many studies have correlated the intratumoural microvessel density (MVD) and incidence of metastasis and/or patient survival in a wide variety of cancers, including bladder cancer [36,44]. More, the tumour development in $\mathrm{BEH}$ is responsible for the macroscopic thickening of the bladder wall [15], this increased thickness can be used to diagnosis BEH using ultrasound [19].

Thus, the present study aimed to determine the pathological aspects of the bladder vasculature and assess the expression of MMP-2 in neoplastic bladder lesions to correlate them with neoplastic alterations and tumour progression.

\section{MATERIALS AND METHODS}

\section{Sampling}

In total, 40 bladders with macroscopic lesions and haematuria were collected from a slaughterhouse in Muniz Freire, state of Espírito Santo-ES, which receives animals from the municipalities in the Caparaó microregion, where Pteridium aquilinum has been documented.

The collection of the bladders was authorised by the Institute for the Agricultural and Forest Protection of Espírito Santo [Instituto de Defesa Agropecuária e Florestal do Espírito Santo (IDAF-ES)].
Urine was collected with the bladder, placed in $10 \mathrm{~mL}$ glass tubes, centrifuged and analyzed using a Neubauer chamber to assess the presence of macrohaematuria or microhaematuria. Only bladders that had blood in the urine were used in the study.

The collected bladders were transported to the Animal Pathology Department of the Federal University of Espírito Santo [Universidade Federal do Espírito Santo - UFES] and were sectioned using scissors along the ventral surface in the caudal-cranial direction. Each bladder was stored in a vial containing $10 \%$ formalin and was divided into four quadrants. A fragment was collected from each quadrant, thus yielding four samples per bladder. When more than one tumour was detected in a quadrant, a fragment was collected from each tumour mass. In quadrants where there were no visible lesions, a random fragment was collected from the centre of the quadrant.

After removal, the samples were stored in plastic cassettes and underwent routine histological processing for paraffin embedding. Three-micrometrethick histological sections were then prepared using a microtome and placed on histological slides. The material was stained using the Hematoxylin-Eosin (HE) and Weigert's resorcin-fuchsin staining methods [17,54]. After staining, the slides were dehydrated and mounted.

\section{Bladder morphometry}

The material stained using the HE method underwent a general assessment of the morphological changes and classification of the lesions, which were classified as neoplastic or non-neoplastic, following the methodology described by Peixoto et al. [30].

The morphometric analysis was performed using a microscope coupled to an eyepiece camera Dino Lite \& Dino Eye $e^{1}$ and the image analysis program DinoCapture ${ }^{1}$ 2.0. The thickness of the urothelium was measured from the basement membrane to the apex of the epithelium. A total of 10 measurements were performed along each sample, and the final thickness was established by taking the mean of all 10 measurements. The measurements were expressed in micrometers.

After compiling the data, analysis of variance (ANOVA) followed by a $t$-test at a $5 \%$ significance level were used to determine the significance of the results.

\section{Bladder vasculature}

Microscopically, the lesions were differentiated as neoplastic or non-neoplastic, and the vascular 
changes were characterized as vascular proliferation, ectasia, dilation and thickening according to the methodology described by Oliveira [28].

The material stained using the Weigert's resorcin-fuchsin method was used to evaluate sclerosis and the vascular fibroelastosis grade according to the classification described by Inoue et al. [20]. Ten arterioles in each sample were evaluated using a 40x objective. A score was provided for the fibroelastosis grade for each arteriole, and at the end of the analysis, the mean value of ten arterioles was calculated to achieve an adequate classification.

All the data obtained during the experiment were compiled and analyzed using descriptive statistical analysis. For each variable studied, the nonparametric Mann-Whitney statistical test was applied, adopting a $5 \%$ significance level.

\section{Expression of metalloproteinase-2}

Bladder samples that showed signs of neoplasm in the HE is staining were used for immunohistochemistry using a clone 42-5D11 anti-human MMP-2 monoclonal antibody ${ }^{2}$.

For this procedure, the slides were initially immersed in $70 \%$ alcohol, dried and then immersed in a poly-L-lysine-based liquid glue. Three-micrometrethick histological sections were sectioned using a rotary microtome, and the slides were then incubated in an oven at $60^{\circ} \mathrm{C}$ for $24 \mathrm{~h}$ to fix the tissue to the slides. The slides were deparaffinised, and the sections were then hydrated and treated with 1:9 hydrogen peroxide in methanol solution for 10 min to block any endogenous peroxidase activity.

For antigen retrieval, a $10 \mathrm{mM}$ citrate buffer solution, $\mathrm{pH}$ 6.0, was applied to the material, which was then placed in an autoclave at maximum power and incubated for $20 \mathrm{~s}$ after the pressure reached $1 \mathrm{~atm}$. The material was then cooled to room temperature. After this procedure, the samples were washed with Trizma ${ }^{3}$ $\mathrm{pH}$ 7.4, and blocked against nonspecific protein binding using $3 \%$ Molico $^{4}$ powdered milk dissolved in Tris buffer for one hour.

The primary antibody incubation step was performed by diluting the antibody in Tris buffer containing $1 \%$ bovine serum albumin and then incubating the sample in a humid chamber for $18 \mathrm{~h}$ at $4^{\circ} \mathrm{C}$. The following day, the slides were washed in a Tris solution and incubated with the secondary antibody for $30 \mathrm{~min}$ at room temperature. The slides were again washed in a
Tris solution and incubated with a Novolink Max Polymer Detection System ${ }^{5}$ according to the manufacturer's instructions. The slides were then washed again with a Tris buffer and treated with a 3,3'-diaminobenzidine, DakoCytomation K3466 ${ }^{6}$, solution for three minutes at room temperature for visualisation of the reaction. The sections were then counterstained with Harris' hematoxylin for $15 \mathrm{~min}$, and next, the slides were washed in running water for $10 \mathrm{~min}$, dehydrated and mounted in synthetic resin.

The processed slides were analysed for MMP-2 immunostaining with the anti-MMP-2 antibody. For the slides that exhibited staining, the staining intensity was evaluated and scored as mild, moderate or intense. The types of cells that were stained with the anti-MMP-2 antibody were also evaluated.

After compiling the data, the non-parametric chi-squared statistical test was used to analyze the results, followed by a contingency test, adopting a 5\% significance level.

\section{RESULTS}

All 40 samples selected during the collection process exhibited macroscopic lesions that were classified as petechiae, papillomatous lesions, haemangiomatous lesions, plaques or whitish depressed lesions. More than one type of macroscopic lesions can be found in a single bladder.

Microscopically, non-neoplastic lesions found in the urothelium included clear cell metaplasia, dysplasia, hyperplasia, haemorrhage, cystitis cystica and Brunn's nests. The following abnormalities were observed in the lamina own: inflammation, vascular proliferation, haemorrhage, vascular ectasia, vascular dilation and vascular thickening. These non-neoplastic lesions were observed in all the bladders tested, including the neoplastic bladders. Non-neoplastic lesions are often observed in the bladders of cattle with BEH.

The microscopic evaluation of the bladders made it possible to characterise the different types of neoplasms present in these samples. The following neoplasms were found among the neoplastic bladder samples: haemangioma, myxoma, transitional cell carcinoma, adenocarcinoma, in situ carcinoma and haemangiosarcoma.

The morphometric analysis of the bladder epithelium of the non-neoplastic bladders revealed that its average height was $116.360 \mu \mathrm{m}$ in quadrant $\mathrm{A}, 120.749$ $\mu \mathrm{m}$ in quadrant $\mathrm{B}, 99.684 \mu \mathrm{m}$ in quadrant $\mathrm{C}$ and 105.944 
$\mu \mathrm{m}$ in quadrant $\mathrm{D}$. In four of the quadrants, it was not possible to measure the thickness of the epithelium due to the loss of the epithelium during histological processing. Figure 1 shows some of the morphological changes observed in the bladders and the epithelium measurements.

The morphometric analysis of bladder epithelium from neoplastic bladders showed that the mean height was $186.436 \mu \mathrm{m}$ in quadrant $\mathrm{A}, 168.927 \mu \mathrm{m}$ in quadrant $\mathrm{B}, 198.390 \mu \mathrm{m}$ in quadrant $\mathrm{C}$ and 164.820 $\mu \mathrm{m}$ in quadrant $\mathrm{D}$. Figure 2 illustrates one of the types of neoplasms observed in the bladders and shows the epithelium measurements of the samples.

The statistical analysis revealed that the urothelium thickness in each bladder did not differ between the quadrants, i.e., the mean epithelial thicknesses of quadrants $\mathrm{A}, \mathrm{B}, \mathrm{C}$ and $\mathrm{D}$ of the same bladder were similar. This was observed in both bladders without neoplasms $(P=0.599)$ and bladders with neoplasms $(P=0.8321)$.

A comparative evaluation of the mean epithelial thickness between bladders by quadrant revealed that there was a difference in the urothelium thickness for bladders with neoplasms and those without neoplasms $(P<0.05)$. The results are shown in Table 1.

Upon evaluating the difference between the epithelium thickness of a neoplastic bladder and a non-neoplastic bladder, regardless of quadrant, a significant difference was observed $(P=0.0001)$. The mean thickness of the bladders without neoplasms was $104.5391 \mu \mathrm{m}$, whereas the mean thickness for bladders with neoplasms was $179.643 \mu \mathrm{m}$.

The evaluation of the vasculature of the urinary bladder without neoplasms revealed that $100 \%$ of the samples exhibited vascular proliferation, $57.14 \%$ exhibited ectasia, $92.86 \%$ exhibited dilation and $50 \%$ exhibited vascular thickening. In bladders with neoplasms, $100 \%$ of the samples exhibited vascular proliferation, $33.33 \%$ exhibited ectasia, $91.67 \%$ exhibited dilation and $83.33 \%$ exhibited vascular thickening.

The Mann-Whitney statistical tests used to find correlations between the types of vascular changes in neoplastic and non-neoplastic bladders revealed significant differences for the variables vascular proliferation and thickening. In non-neoplastic bladders, the values for vascular proliferation $(P=0.0037)$ and vascular thickening $(P=0.0007)$ were lower than those in neoplastic bladders. There were no significant differences for the parameters dilatation $(P=0.4735)$ and vascular ectasia $(P=0.6083)$.
Vascular changes were very evident in the bladders of animals with haematuria and were found in both neoplastic and non-neoplastic samples. The present study showed a prevalence of vascular proliferation and dilatation in the bladders examined. This finding suggests that in animals with haematuria, these lesions are common and cause the intermittent loss of blood and, hence, the death of the animals by anaemia.

The analysis of the fibroelastosis grade revealed that $57.5 \%(23 / 40)$ of the samples were classified as Grade I, 10\% (4/40) as Grade II, 2.5\% (1/40) as Grade III and none as Grade IV fibroelastosis. In $30 \%$ (12/40) of the bladders, there were no observable forms of fibroelastosis. There was a significant difference $(P<0.0001)$ in the fibroelastosis grade between the neoplastic and non-neoplastic bladders, i.e., the fibroelastosis grade was higher in the neoplastic bladders than in the non-neoplastic bladders.

Figure 3 illustrates the vascular changes and the fibroelastosis grade observed in the bladders of animals with enzootic haematuria. In all the neoplastic samples evaluated, $100 \%$ were positive for MMP-2, although the staining intensity differed between the different types of neoplasms (Figure 4).

In this study, an irregular staining intensity of the neoplastic tissue was observed. In the adenocarcinomas, mild staining was observed in 2/6 (33\%) of the samples, moderate staining in $1 / 6(17 \%)$ and intense staining in $3 / 6(50 \%)$. In the transitional cell carcinomas, mild staining was observed in $3 / 8(37.5 \%)$ of the samples, 3/8 (37.5\%) exhibited moderate staining and $2 / 8(25 \%)$ exhibited intense staining. In the two samples of in situ carcinomas evaluated, $100 \%$ exhibited intense staining. In the myxomas, $1 / 4$ (25\%) of the samples exhibited mild staining, and 3/4 (75\%) exhibited moderate staining, whereas no samples exhibited intense staining. In the haemangiomas, 10/12 (83.3\%) of the samples exhibited moderate staining, 2/12 (16.7\%) exhibited intense staining and none of the samples exhibited mild staining. For the haemangiosarcoma, 1/1 (100\%) of the samples exhibited moderate staining.

The statistical analysis indicated that there was a significant increase $(P<0.05)$ in the expression of MMP2 in the neoplasms of mesenchymal origin compared to the neoplasms of epithelial origin. Regarding the mild, moderate and severe staining intensities, regardless of the type of neoplasm, moderate staining was significantly different compared to the other staining intensities $(P<0.05)$. 


\section{DISCUSSION}

As mentioned before, macroscopic lesions in addition to haematuria, polypoid lesions and raised lesions [41], wall thickening, papillomatous lesions and petechiae [15] and haemorrhagic lesions, such as petechiae and ecchymosis, are frequently seen, and haematuria may be associated with these vascular lesions and not be exclusively a consequence of neoplasia. It is believed, however, that the existence of different lesions is likely associated with different types of neoplasms in bladders. Tumours vary in their macro and microscopic appearance, which leads to morphological differences between the samples.

Several studies report a large variety of nonneoplastic microscopic findings in BEH. There are reports of hyperplasia and metaplasia, as well as vascular proliferation, inflammation, haemorrhage, vascular ectasia, dysplasia, cystic cystitis and Brunn's nests [30,40]. Metaplasia and atypia have also been reported than in buffalo raised on pastures with bracken [22]. This variety of findings indicates the possibility

Table 1. Mean thicknesses of the quadrants of neoplastic and non-neoplastic bladders (expressed in $\mu \mathrm{m}$ ) and the differences between the quadrants according to a $t$-test at a $0.05 \%$ significance level.

\begin{tabular}{|c|c|c|c|}
\hline Quadrant & \multicolumn{2}{|c|}{ Mean thickness $[\mu \mathrm{m}]$} & $P$ [unilateral] \\
\hline & Non-neoplastic & Neoplastic & \\
\hline $\mathrm{A}$ & 116.3605 & 186.436 & 0.0089 \\
\hline $\mathrm{B}$ & 120.7498 & 168.9269 & 0.0216 \\
\hline $\mathrm{C}$ & 99.6836 & 198.3903 & 0.019 \\
\hline $\mathrm{D}$ & 105.9441 & 164.8201 & 0.0036 \\
\hline
\end{tabular}

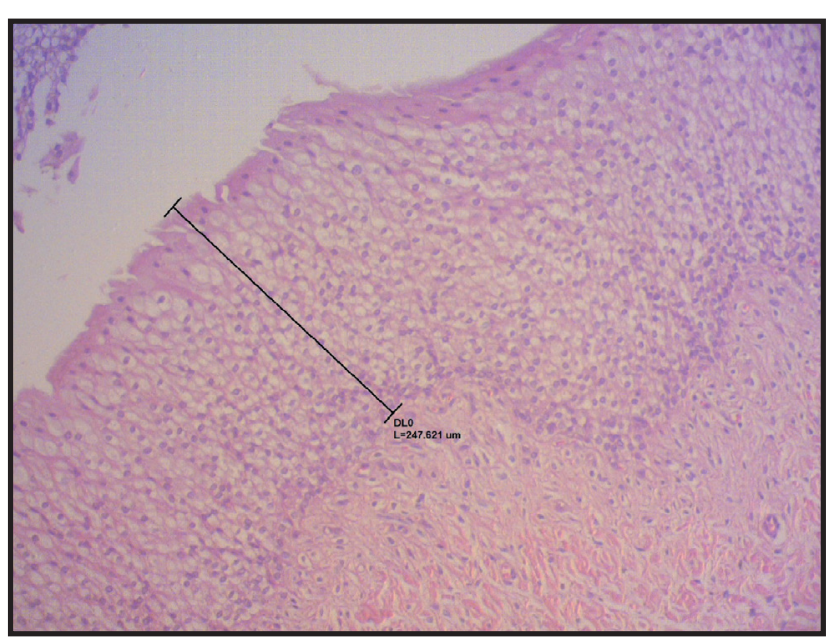

Figure 1. Photomicrograph of a bovine bladder, sample P244/10A, illustrating dysplasia and hyperplasia of the bladder epithelium and the epithelium measurements of the sample [HE; 10x]. of the involvement of other factors concomitant with BEH. Epithelial hyperplasia and metaplasia, for example, may be the result of damage caused by bovine papilloma virus type 2 , in which BPV-2 infection can act synergistically with cancerous compounds in the bracken, thus contributing to the generation of different lesions in the bladder [34].

The data from the microscopic evaluation of the bladders are consistent with the observations described in the literature [30,39]. Among the neoplastic bladder samples, between one and four types of neoplasms were found in the same sample. Studies show that bladder tumours are common in animals with $\mathrm{BEH}$ and that neoplasms have different microscopic classifications [18,32]. It is believed that the bladder has the capacity to generate various types of neoplasms due to the different histological components of the bladder, thus enabling it to generate both mesenchymal and epithelial lesions. In our study, we observed the coexistence of non-neoplastic and neoplastic lesions, a phenomenon that has been previously reported $[22,30]$.

Regarding the distribution of neoplasms in each region of the bladder of cattle with $\mathrm{BEH}$, a higher occurrence of neoplasms has been reported in quadrants $C$ and D (caudal) than in quadrants A and B (cranial) [38]. However, only the presence or absence of neoplastic lesions in each quadrant was considered, differently from what was done in our study, which performed random measurements. The collection of ten measurements of epithelial height in this study along the entire length of each sample of the bladder allowed to calculate an average and, therefore, this value does not express the exact measurement of the area affected by the neoplasm.

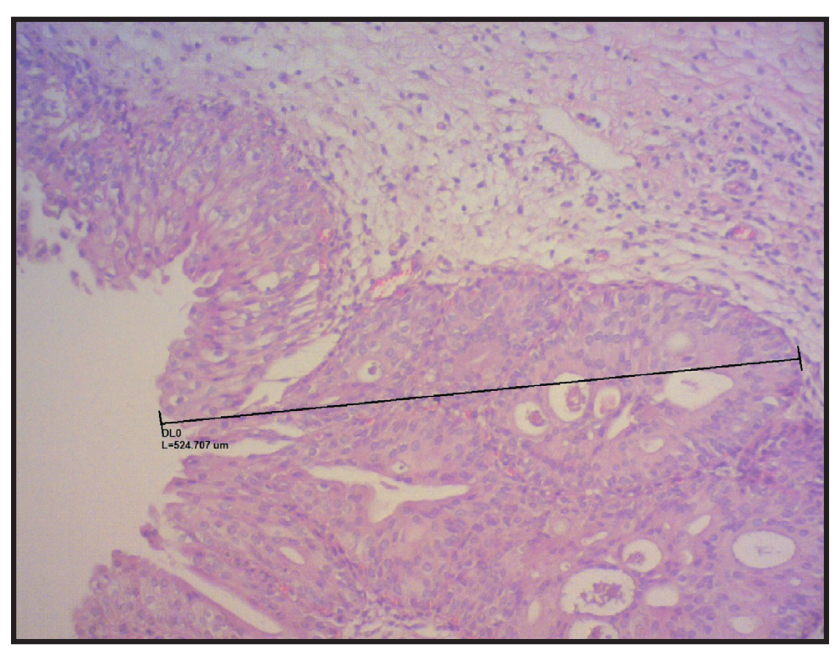

Figure 2. Photomicrograph of bovine bladder, sample P241/10A, illustrating a transitional cell carcinoma lesion and epithelium measurements of the sample [HE; 10x]. 


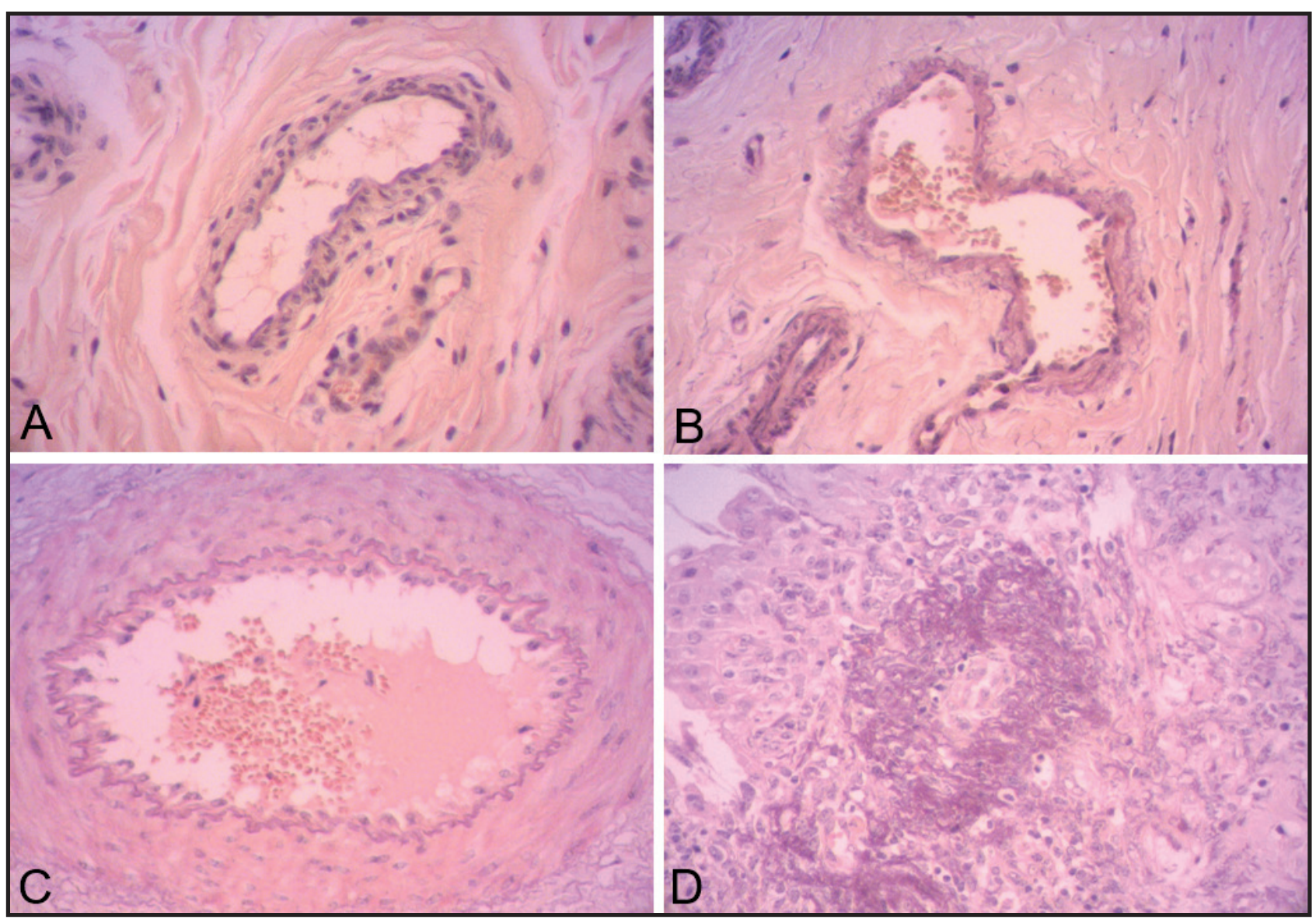

Figure 3. Photomicrograph of a bovine bladder with enzootic haematuria, revealing different fibroelastosis grades [Weigert's resorcin-fuchsin staining; 20x]. A- Arteriole without fibroelastosis (sample P454/10). B- Arteriole with ectasia and Grade I fibroelastosis (sample P456/10). C- Arteriole with Grade II fibroelastosis (sample P226/10). D- Arteriole with Grade III fibroelastosis in the intratumoural vasculature of an adenocarcinoma (sample P229/10).

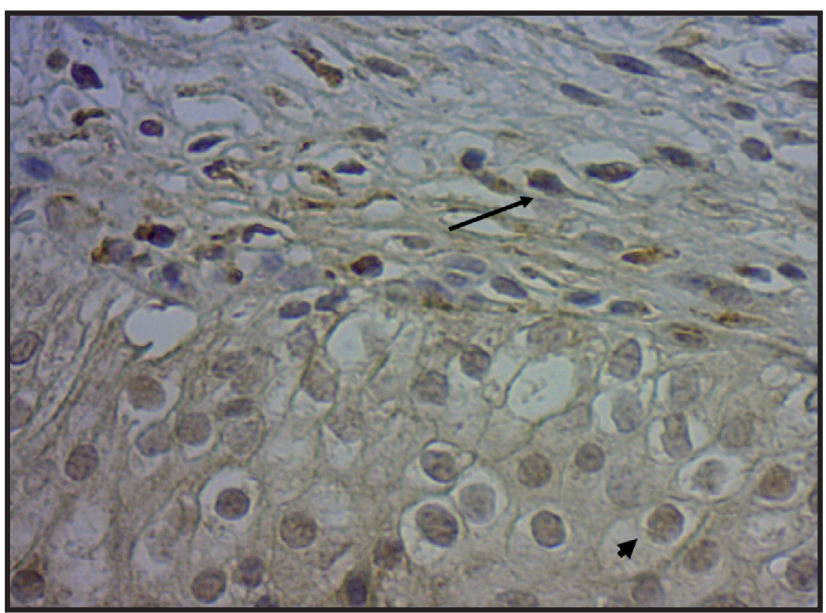

Figure 4. Photomicrograph of a bovine bladder with enzootic haematuria, revealing positive staining for MMP-2 in epithelial cells (arrowhead) and fibroblasts (arrow) [Immunohistochemical staining MMP-2 (1:200); 40x]. (sample P241/10).

It is worth noting that among the common types of neoplasms in animals with BEH, there were various patterns of cell growth, which contributes to the differences in thickness observed in the urothelium of these animals. Tumours with both exophytic and endophytic characteristics have been observed [22]. Transition cell carcinoma, for example, is a neoplasm that is more com- monly found in the bladder and although spontaneous development of this type of neoplasm is normally rare in cattle, its prevalence is high in areas with $\mathrm{BEH}$ [24].

Thus, it is possible to infer that the irregularity with which neoplastic lesions develop throughout the bladder tissue in animals with BEH does allow for the occurrence of both areas with significant cell proliferation and areas with less cell proliferation or even areas with no neoplastic lesion in the same sample, which therefore results in a low epithelium height. In addition, various tumour types also result in different urothelium measurements. In this study, several samples displayed neoplasms in more than one quadrant, and this finding may possibly explain the greater homogeneity of the measurement values.

Ultrasonographic images of the bladders of animals with neoplasms confirm this characteristic of neoplastic growth, since the image generated during the examination shows an irregular mass along the bladder wall [24]. The samples used in this study were randomly collected, and there was no clear pattern regarding the presence of neoplasms, i.e., neoplasms 
were distributed in all of the quadrants and were not more frequently observed in a specific quadrant, as assessed by the morphometric analysis.

Although the bladders without neoplastic changes analysed herein exhibited other types of lesions, such as dysplasia and hyperplasia, the cell proliferation observed in bladders with neoplasms resulted in a thicker epithelium in these bladders. This finding can be explained by the fact that cell growth occurs much faster in neoplastic processes than in normal tissue [24].

The thickness of the urothelium was greater in all the quadrants with neoplasms compared to the quadrants without neoplasms. These data suggest that it is possible to achieve an early diagnosis of BEH with the use of more detailed imaging diagnostic techniques by identifying changes in the urothelium thickness. These data confirm that the diagnosis of this disease can be made before the onset of clinical signs, analysing the contours and thickness of the bladder wall through ultrasound examination [19]

Upon evaluating the difference between the epithelium thickness of a neoplastic bladder and a nonneoplastic bladder, regardless of quadrant, a significant difference was observed. The mean thickness of the bladders without neoplasms was $104.5391 \mu \mathrm{m}$, whereas the mean thickness for bladders with neoplasms was $179.643 \mu \mathrm{m}$. Therefore, it is possible to differentiate between the abnormal cell growth in neoplastic samples and the normal tissue found in non-neoplastic tissue using morphometric analyses. Although it cannot provide a definitive diagnosis, changes in the urothelial thickness are indicative of the type of lesion observed (neoplastic or non-neoplastic).

\section{Bladder vasculature}

The evaluation of the vasculature of the urinary bladder, was observed vascular endothelial neoplasms in cattle with $\mathrm{BEH}$ that formed projections in the bladder mucosa [41]. Oedema, haemorrhage and multifocal lymphoplasmacytic infiltrates were frequently observed in the bladder mucosa (haemorrhagic cystitis) of these animals. Therefore, these authors suggested that neoplasms of diverse histogenesis are responsible for chronic haematuria and consequent anaemia, accompanied by the loss of the epithelial lining integrity of the bladder mucosa.

Moreover, the vascular changes described in cases of BEH may cause bleeding in the bladder wall or lumen, and haemangiomatous changes can develop in these areas. Such changes lead to macrohaematuria, which occurs in some cases without the development of neoplastic lesions [26].

The vascular proliferation and thickening were significant in bladders with neoplasms, which may be explained by the fact that tumours require an extensive vascular supply. In addition, many tumours release vascular growth factors and promote neovascularisation.

Fibroelastosis in humans is common in the endocardium and is known as endocardial fibroelastosis (EFE). EFE behaves as a cardiomyopathy and is characterised by endocardial thickening that leads to decreased ventricular volume and consequent heart failure [27]. In mares, fibroelastosis has been detected in animals with endometriosis and its prevalence is related to the increasing age of these animals [20]. In the present study, fibroelastosis was more severe in bladders with neoplasms; however, to date, there have been no reports of these changes in animals with $\mathrm{BEH}$.

Studies examining the tumor vasculature are relevant and many show correlations between intratouroural microvessel density (MVD), levels of vascular endothelial growth factor (VEGF) and the incidence of metastases and/or patient survival in a variety of cancers, including bladder cancer $[35,44]$. The growth and metastasis of solid tumours relies on their ability to initiate and sustain the growth of new blood vessels, i.e., angiogenesis [27]. Thus, the study of the bladder vasculature is increasingly important and may aid in tumour progression studies.

Several studies have demonstrated the expression of MMP-2 in tumour samples. In canine breast carcinomas, an increase in MMP-2 and MT1-MMP was observed [29]. The expression of MMP-2 has also been described in neoplastic cells and/or stromal cells of cervical carcinomas [12], as well as in stroma of colorectal carcinomas and in squamous cell carcinomas of the tongue $[8,48]$.

An unresolved issue in cancer biology is the spatio-temporal expression of MMPs in tumours and their significance in cancer progression [10]. To aid in determining the role of MMPs in the invasiveness of bladder cancer, a study using an MMP-2 blocking antibody, allowed the observation of a $50 \%$ to $60 \%$ reduction in tumour invasion compared to a control group [21].

As for the localisation of MMP-2 in the tumour samples, the cell types that showed positive MMP-2 staining were epithelial cells, fibroblasts, 
endothelial cells and smooth muscle cells. MMPs were observed with variable frequency in ductal cells, muscle fibres, sebaceous glands and collagen fibres [2]. Fibroblasts and endothelial cells were stained in some regions, with intense expression in the areas undergoing angiogenesis [6].

Significant variation in staining intensity has been reported when evaluating MMP-2, MMP-9, TIMP-1 and TIMP-2 in basal cell carcinomas where strong immunostaining of these antigens was seen more frequently in the adjacent epidermis than in the tumour itself [33]. It has also been reported that the intensity of staining and the proportion of cells that express metalloproteinases, including MMP-2, are heterogeneous [2], which is consistent with the results of the present study.

The statistical analysis indicated that there was a significant increase in the expression of MMP-2 in the neoplasms of mesenchymal origin compared to the neoplasms of epithelial origin. This result could be based on the fact that MMP-2 plays an important role in angiogenesis, tumour progression and the metastatic spread of cancer $[4,29,35,45]$ and that its increased expression has been observed in various types of malignant tumors $[9,42,45,47]$.

Regarding the mild, moderate and severe staining intensities, regardless of the type of neoplasm, moderate staining was significantly different compared to the other staining intensities. In a study with 30 squamous cell carcinoma specimens, $60 \%$ exhibited some degree of positivity for MMP-2, and in $30 \%$ of cases, this staining was considered moderate or intense [2]. Similar results in which $39.5 \%$ and $34.1 \%$ of the respective samples exhibited moderate or intense immunoreactivity for MMP-2, was reported [7,16]. In the papillary carcinomas the reactivity of MMP-2 was weak in one case, moderate in 10 cases and strong in nine cases [7]. The three cases of Hurthle cell carci- noma showed moderate immunostaining. However, in the human serum with urothelial bladder carcinoma and was found that high serum levels of VEGF-D and low level of MMP-2 predicted lymph node metastases at the time of radical cystectomy [3].

Given the low number of samples with a given type of neoplasm and the heterogeneity of the staining in the different types of neoplasms, it was not possible to establish any relationship between the MMP-2 expression and tumour malignancy.

\section{CONCLUSION}

We conclude that the urothelium of animals with bovine enzootic haematuria presents different non-neoplastic and neoplastic lesions that cause thickening of the bladder wall. Vascular proliferation, fibroelastosis and MMP-2 expression were higher in neoplastic lesions. However, MMP-2 expression was higher in mesenchymal neoplasms.

\section{MANUFACTURERS}

\author{
${ }^{1}$ Mibex Comércio de Equipamentos Eireli - EPP. São Paulo, SP, \\ Brazil. \\ ${ }^{2}$ RDI-Research Diagnostics Inc. Flanders, NJ, USA. \\ ${ }^{3}$ Sigma Chemical C.O. St. Louis, MO, USA. \\ ${ }^{4}$ Nestlé do Brasil Ltda. São Paulo, SP, Brazil. \\ ${ }^{5}$ Leica Biosystems Nussloch GmbH. Buffalo Grove, IL, USA. \\ ${ }^{6}$ DakoCytomation Inc. Carpinteria, CA, USA.
}

Funding. The authors declarator that received financial support for the research of the Foundation for Research and Innovation Support of Espírito Santo (Fundação de Amparo à Pesquisa e Inovação do Espírito Santo - FAPES), protocol number 45440409/2009.

Ethical approval. This experimental protocol was approved by the Ethics Committee of UFES, under case number 019/2010.

Declaration of interest. The authors declare that there is no conflict of interest. Authors alone are responsible for the content and writing of the article.

\section{REFERENCES}

1 Aranha P.C., Hansen H.C., Rasmussen L.H., Strobel B.W. \& Friis C. 2014. Determination of ptaquiloside and pterosin B derived from bracken (Pteridium aquilinum) in cattle plasma, urine and milk. Journal of Chromatography B. 1(951-952): 44-51.

2 Barros S.S.L.V. 2006. Expressão Imuno-histoquímica de metaloproteinases em carcinoma epidermóide de lábio inferior e língua. 128f. Natal, RN. Tese (Doutorado em Patologia Oral) - Programa de Pós-Graduação em Patologia Oral, Universidade Federal do Rio Grande do Norte.

3 Benoit T., Keller E.X., Wolfsgruber P., Hermanns T., Günthart M., Banzola I., Sulser T., Provenzano M. \& Poyet C. 2015. High VEGF-D and Low MMP-2 Serum Levels Predict Nodal-Positive Disease in Invasive Bladder Cancer. Medical Science Monitor. 21: 2266-2274. 
4 Bergers G., Brekken R., McMahon G., Vu T.H., Itoh T., Tamaki K., Tanzawa K., Thorpe P., Itohara S., Werb Z. \& Hanahan D. 2000. Matrix metalloproteinase-9 triggers the angiogenic switch during carcinogenesis. Nature Cell Biology. 2(10): 737-744.

5 Birkedal-Hansen H., Moore W.G., Bodden M.K., Windsor L.J., Birkedal-Hansen B., DeCarlo A. \& Engler J.A. 1993. Matrix Metalloproteinases: a Review. Critical Reviews in Oral Biology \& Medicine. 4(2): 197-250.

6 Campo E., Merino M.J., Liotta L., Neumann R. \& Stetler-Stevenson W. 1992. Distribution of the 72-kd type IV collagenase in nonneoplastic and neoplastic thyroid tissue. Human pathology. 23(12): 1395-1401.

7 Cavalheiro B.G. 2006. Expressão das metaloproteinases MMP-2, MT1-MMP e TIMP-2 e aspectos clinicopatológicos no carcinoma medular da glândula tireóide: implicações prognósticas. 248f. São Paulo, SP. Tese (Doutorado em Ciências) - Faculdade de Medicina, Universidade de São Paulo.

8 Chan C.C., Menges M., Orzechowski H.D., Orendain N., Pistorius G., Feifel G., Zeitz M. \& Stallmach A. 2001. Increased matrix metalloproteinase 2 concentration and transcript expression in advanced colorectal carcinomas. International Journal of Colorectal Disease. 16(3): 133-140.

9 Clark I.M., Swingler T.E., Sampieri C.L. \& Edwards D.R. 2008. The regulation of matrix metalloproteinases and their inhibitors. International Journal of Biochemistry \& Cell Biology. 40(6-7): 1362-1378.

10 Clutterbuck A.L., Harris P., Allaway D. \& Mobasheri A. 2001. Matrix metalloproteinases in inflammatory pathologies of the horse. Veterinary Journal. 183(1): 27-38.

11 Costa R.M.G., Bastos M.M., Oliveira P.A. \& Lopes C. 2012. Bracken-associated human and animal health hazards: chemical, biological and pathological evidence. Journal of Hazardous Materials. 15: 203-204.

12 Davidson B., Goldberg I., Kopolovic J., Lerner-Geva L., Gotlieb W.H., Ben-Baruch G. \& Reich R. 1999. MMP-2 and TIMP-2 expression correlates with poor prognosis in cervical carcinoma--a clinicopathologic study using immunohistochemistry and mRNA in situ hybridization. Gynecologic Oncology. 73(3): 372-382.

13 Drury R.A.B., Wallington E.A. \& Cameron R. 1967. Connective Tissue Fibers. In: Carleton H.M., Drury R.A.B. \& Wallington E.A. (Eds). Carleton's Histological Techniques. 4th edn. New York: Oxford University Press, pp.166-181.

14 Ellis L.M. \& Fidler I.J. 1996. Angiogenesis and metastasis. European Journal of Cancer. 32(14): 2451-2460.

15 Falbo M.K., Kommers G.D., Masuda E.K., Fighera R.A., Piazer J.V.M., Barros C.S.L., Martins T.B. \& Rosa F.B. 2005. Alterações hematológicas, bioquímicas, urinárias e histopatológicas na intoxicação natural em bovinos pela samambaia Pteridium aquilnum (L.) Kühn. Semina. 26(7): 547-558.

16 Franchi A., Santucci M., Masini E., Sardi I., Paglierani M. \& Gallo O. 2002. Expression of matrix metalloproteinase 1, matrix metalloproteinase 2, and matrix metalloproteinase 9 in carcinoma of the head and neck. Cancer. 95(9): 19021910.

17 Furlan F.H., Mendes E.R.S., Ducatti K.R., Marcon G.C., Dombrosky T., Amorim T.M. \& Riet-Correa F. 2014. Intoxicação aguda por Pteridium aracnoideum e Pteridium caudatum em bovinos e distribuição das plantas em Mato Grosso. Pesquisa Veterinária Brasileira. 34(4): 343-348.

18 Galvão A., Brito M.F., Aragão A.P., Yamasaki E.M., Peixoto P.V. \& Tokarnia C.H. 2012. Sobrevivência/viabilidade de bovinos com hematúria enzoótica após transferência para região livre de Pteridium. Pesquisa Veterinária Brasileira. 32(9): 887-902.

19 Hoque M., Somvanshi R., Singh G.R. \& Mogha I.V. 2002. Ultrasonographic evaluation of urinary bladder in normal, fern fed and enzootic bovine haematuria-affected cattle. Journal of Veterinary Medicine. 49(8): 403-407.

20 Inoue Y., Ito K., Tereda T., Nishimura N., Hatazoe T. \& Sato K. 2000. Degenerative changes in the endometrial vasculature of the mare detected by videoendoscopic examination. Proceedings of the AAEP Convention. 46: 325-329.

21 Kumar B., Koul S., Petersen J., Khandrika L., Hwa J.S., Meacham R.B., Wilson S. \& Koul H.K. 2010. p38 mitogen-activated protein kinase-driven MAPKAPK2 regulates invasion of bladder cancer by modulation of MMP-2 and MMP-9 activity. Cancer Research. 70(2): 832-841.

22 Maiolino P., Ozkul A., Sepici-Dincel A., Roperto F., Yücel G., Russo V., Urraro C., Lucà R., Riccardi M.G., Martano M., Borzacchiello G., Esposito I. \& Roperto S. 2013. Bovine papillomavirus type 2 infection and microscopic patterns of urothelial tumors of the urinary bladder in water buffaloes. BioMed Research International. 2013: 937918. DOI: $10.1155 / 2013 / 937918$

23 Mccawley L. \& Matrisian L.M. 2000. Matrix metalloproteinases: multifunctional contributors to tumor progression. Molecular Medicine Today. 6(4): 149-156. 
24 Meuten D.J \& Meuten T.L.K. 2020. Tumors of the Urinary system. In: Meuten D.J. (Ed). Tumors in domestic animals. 5th edn. Ames: Wiley-Blackwell, pp.632-688.

25 Morris J. \& Dobson J. 2001. Urinary tract. In: Small Animal Oncology. Oxford: Blackwell Science, pp.154-165.

26 Newman S.J., Confer A.W. \& Panciera R.J. 2009. Sistema urinário. In: McGavin M.D. \& Zachary J.F. (Eds). Bases de Patologia em Veterinária. 4.ed. Rio de Janeiro: Elsevier, pp.613-691.

27 Noronha L., Hecke F.A.F., Magalhães T.A., Pinheiro D.L. \& Cat I. 2004. Estudo de 11 casos de fibroelastose endocárdica primária. Jornal Brasileiro de Patologia e Medicina Laboratorial. 40(4): 261-264.

28 Oliveira L.G.P. 2009. Novos aspectos patológicos e patogenéticos da hematúria enzoótica bovina. 141f. Seropédica, RJ. Dissertação (Mestrado em Clínica e Cirurgia Veterinária) - Programa de Pós-Graduação em Medicina Veterinária, Universidade Federal Rural do Rio de Janeiro.

29 Papparella S., Restucci B., Paciello O. \& Maiolino P. 2002. Expression of matrix metalloprotease-2 (MMP-2) and the activator membrane type 1 (MT1-MMP) in canine mammary carcinomas. Journal of Comparative Pathology. 126(4): 271-276.

30 Peixoto P.V., França T.N., Barros C.S.L. \& Tokarnia C.H. 2003. Histopathological aspects of bovine enzootic hematuria in Brazil. Pesquisa Veterinária Brasileira. 23(2): 65-81.

31 Constable P.D., Hinchcliff K.W., Done S.H. \& Grünberg W. 2017. Diseases of the Urinary System. In: Veterinary medicine: A textbook of the diseases of cattle, horses, sheep, pigs and goats, tenth. London: Saunders, pp.1095-1154.

32 Reis S.D.S., Macêdo J.T.S.A., Oliveira R.S., Peixoto T.C., Ferreira M.M., Gasper A.L. \& Pedroso P.M.O. 2016. Enzootic hematuria in cattle from Northeastern Brazil. Brazilian Journal of Veterinary Pathology. 9(2): 78-82.

33 Ribeiro R.I.M.A, Borges Jr. P.C., Cardoso S.V., Candelori I., Espíndola F.S., Cassali G.D. \& Loyola A.M. 2008. Expressão de metaloproteinases de matriz e de seus inibidores teciduais em carcinomas basocelulares. Jornal Brasileiro de Patologia e Medicina Laboratorial. 44(2): 115-121.

34 Roperto S., Brun R., Paolini F., Urraro C., Russo V., Borzacchiello G., Pagnini U., Raso C., Rizzo C., Roperto F. \& Venuti A. 2008. Detection of bovine papillomavirus type 2 in the peripheral blood of cattle with urinary bladder tumours: possible biological role. Journal of General Virology. 89(12): 3027-3033.

35 Schmalfeldt B., Prechtel D., Härting K., Späthe K., Rutke S., Konik E., Fridman R., Berger U., Schmitt M., Kuhn W. \& Lengyel E. 2001. Increased expression of matrix metalloproteinases (MMP)-2, (MMP)-9, and the urokinasetype plasminogen activator is associated with progression from benign to advanced ovarian cancer. Clinical Cancer Research. 7(8): 2394-2404.

36 Shigeru K., Miyata Y. \& Kanetake H. 2006. Current status and perspective of antiangiogenic therapy for cancer: urinary cancer. International Journal of Clinical Oncology. 11(2): 90-107.

37 Silva D.A., Watanabe A.H.Q. \& Marçal W.S. 2016. Avaliação epidemiológica da prevalência da hematuria enzoótica bovina associada a samambaia no Paraná. Publicações em Medicina Veterinária e Zootecnia. 10(2): 125-131.

38 Silva M.A. 2012. Caracterização histopatológica e imunoistoquímica de bexigas de bovinos com hematúria enzoótica. 110f. Alegre, ES. Dissertação (Mestrado em Ciências Veterinárias) - Programa de Pós-Graduação em Ciências Veterinária, Universidade Federal do Espírito Santo.

39 Silva M.A., Sequeira J.L., Madureira A.P. \& Nunes L.C. 2013. Caracterização imunoistoquímica de neoplasias de bexigas associadas à hematúria enzoótica bovina. Semina. 34(1): 281-291.

40 Somvanshi R., Pathania S., Nagarajan N.,Pangty K. \& Kumar P. 2012. Pathological study of non-neoplastic urinary bladder lesions in cattle and buffaloes: a preliminary report. Tropical Animal Health and Production. 44(4): 855-861.

41 Souto M.A.M., Kommers G.D., Barros C.S.L., Rech R.R. \& Piazer J.V.M. 2006. Neoplasmas da bexiga associados à hematúria enzoótica bovina. Ciência Rural. 36(5): 1647-1650.

42 Turpeenniemi-Hujanen T. 2005. Gelatinases (MMP-2 and-9) and their natural inhibitors as prognostic indicators in solid cancers. Biochimie. 87(3-4): 287-297.

43 Verhöeff F.H. 1908. Some new staining methods of wide applicability. Including a rapid differential stain for elastic tissue. Journal of American Medical Association. 11: 876-877.

44 Weidner N. \& Folkman J. 1996. Tumoral vascularity as a prognostic factor in cancer. Important Advanced in Oncology. 1996: 167-190.

45 Westermarck J. \& Kähäri V.M. 1999. Regulation of matrix metalloproteinase expression in tumor invasion. FASEB Journal. 13(8): 781-792. 
A.B. Archanjo, N.V. Tamiasso, J.C. Cosme, et al. 2020. Morphometric and Vascular Analyses and MMP-2 Expression in Bladders of Animals with Bovine Enzootic Haematuria. Acta Scientiae Veterinariae. 48: 1737.

46 Wosiacki S.R., Claus M.P., Alfieri A.F. \& Alfieri A.A. 2006. Bovine papillomavius type 2 detection in the urinary bladder of cattle with chronic enzootic haematuria. Memórias do Instituto Oswaldo Cruz. 101(6): 635-638.

47 Yoshizaki T., Sato H. \& Furukawa M. 2002. Recent advances in the regulation of matrix metalloproteinase 2 activation: from basic research to clinical implication. Oncology Reports. 9(3): 607-611.

48 Yoshizaki T., Maruyama Y., Sato H. \& Furukawa M. 2001. Expression of tissue inhibitor of matrix metalloproteinase-2 correlates with activation of matrix metalloproteinase-2 and predicts poor prognosis in tongue squamous cell carcinoma. International Journal of Cancer. 95(1): 44-50. 